
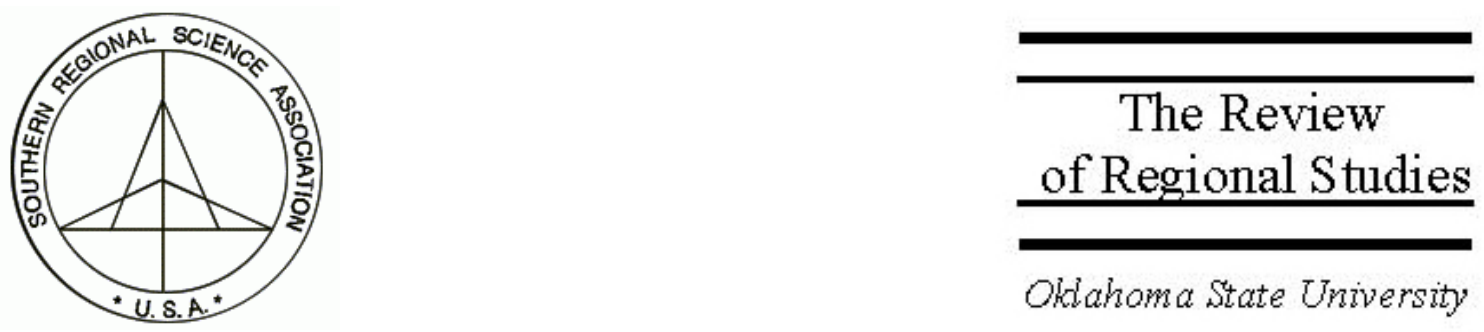

\title{
Foreign Direct Investment: Agglomeration Economies and Returns to Promotion Expenditures
}

\author{
Seong-Hee Kim \\ Department of Economics and Finance, University of Wyoming \\ P.O. Box 3985, Laramie, WY, 82071 \\ Todd S. Pickton \\ Department of Economics and Finance, University of Wyomig \\ P.O. Box 3985, Laramie, WY, 82071 \\ Shelby Gerking \\ Department of Economics, University of Central Florida \\ P.O. Box 161400, Orlando, FL, 32816-1400, email: shelby.gerking@bus.ucf.edu
}

\begin{abstract}
The effect of a state's financial incentives to attract foreign direct investments (FDI) is a frequent topic for both economists and policy makers. Many studies have shown that FDI are disproportionately concentrated in states with agglomeration economies. This paper uses a conditional logit model with FDI (new plants) data from 1987-1994 to explore the relationship between state efforts, state characteristics, and FDI attraction. Key results show that both promotion expenditures and agglomeration economies are important in attracting foreign plants. Results also indicate that promotion expenditures by states with small economies can partially offset location disadvantages of agglomeration (urbanization and/or localization) economies and thus appear to be a useful economic development tool as states compete for investment.
\end{abstract}




\section{INTRODUCTION}

Previous studies have demonstrated that planned new foreign-owned manufacturing plants are disproportionately concentrated in states with larger economies (see, for example, Coughlin and Segev 2000). A possible reason for this outcome is that states with greater population or population density as well as more manufacturing and related activity may offer location advantages because of agglomeration (urbanization and/or localization) economies. Additionally, state and local governments as well as private organizations spend substantial sums of money each year on advertising and financial incentives to attract new foreign direct investment (FDI) projects. Yet, the question of whether economic development efforts pursued by states with smaller economies can at least partially offset the cost/location advantages possessed by states with larger economies has received little attention. The answer here has practical implications for identifying the characteristics of states that make alternative policy tools most effective as well as implications for a broad range of issues, including economic efficiency and human migration patterns. Moreover, to the extent that economic development efforts might lead to spatial dispersion of industry, it may shed light on the economic value of agglomerative forces.

This paper examines links between types of external scale economies, state promotion expenditures, and the location of FDIs in new manufacturing plants among U.S. states. (A related paper in this volume, Brown, Hayes, and Taylor (2003) considers the role of state policies such as the provision of public capital in determining regional growth.) Graham and Krugman (1995) and Leichenko and Erickson (1997) present an overview of the economics of FDIs in the U.S. and summarize the literature on inward FDIs to U.S. regions. One reason for looking at FDIs in new plants is that such investments could, at least in principle, go to any U.S. state (or anywhere in the world for that matter). Also, previous studies of the United States (e.g., Coughlin, Terza, and Arromdee 1991; Friedman, Gerlowski, and Silberman 1992; Head, Ries, and Swenson 1999) have found positive associations between the location of FDI and promotion expenditures and/or variables measuring the presence of localization economies. This study obtains broadly similar results but goes a step further to (1) examine the independent contribution of both urbanization and localization economies to FDI attraction, and (2) quantify the extent of interaction between promotion expenditures and measures of agglomeration economies. A key finding is that promotion expenditures can at least partially compensate for a lack of both urbanization and localization economies. This result is good news for states lacking agglomeration advantages because it suggests an economic development policy tool that may be effective in competing with larger neighbors.

The reminder of this paper is divided into four sections. Section 2 develops an empirical framework to analyze the location of FDIs in new plants. Section 3 describes the data. Section 4 presents results. Implications and conclusions are drawn out in Section 5.

\section{EMPIRICAL FRAMEWORK}

The empirical framework used to model the spatial distribution of FDIs is quite standard; in consequence, it is only briefly described. The approach taken assumes that foreign firms opening new plants in the U.S. attempt to maximize profits. Profits, in turn, are affected by both demand and cost considerations that vary across locations. Available FDI data (see Section 3) 
provide the number of new plants opened by foreign-owned firms by state and by manufacturing industry. Consequently, a discrete choice model (more specifically, a conditional logit model) is used to estimate the probability that state $j$ is the profit-maximizing location in which to make a particular investment. This approach is appropriate (see Greene 2000, pp. 857-865 for details) when (1) the data consist of attributes of choices, such as characteristics of states selected by foreign investors, and (2) errors in the choice process are independent and identically distributed with a Weibull distribution. Additionally, an advantage of the conditional logit model is that estimated interactions between promotion expenditures and measures of agglomeration economies are simple to calculate, intuitively appealing, and of potential interest to policymakers.

The model to be applied can be written as

$$
\text { (1) } P_{j}=\exp \left\{\theta^{T} Z_{j}\right\} / \sum_{j}^{J} \exp \left\{\theta^{T} Z_{j}\right\}
$$

where $P_{j}$ denotes the probability that a foreign investor chooses state $j$ from a total of $J$ alternative states, $Z_{j}$ denotes characteristics of state $j$, and $\theta$ denotes a vector of coefficients to be estimated. Conditional logit models have been widely used in previously cited empirical studies of inward FDIs to U.S. states as well as by List and Co (2000). In equation (1), each FDI is treated as an observation; the idea behind estimation is to compare attributes of the state selected with attributes of other states. McFadden (1974) suggests a sampling technique used by Friedman, Gerlowski, and Silberman (1992) to reduce computational effort when the number of alternative choices is large. That method is not employed here; instead for each FDI considered, attributes of the selected state are compared to attributes of all other states in the data set.

\section{DATA}

The conditional logit model estimates determinants of the number of planned new plant investments by foreign firms in each of the 48 contiguous U.S. states for the eight-year period 1987-1994. New plants are defined as new operating facilities, established by a foreign-owned productive enterprise or as a new foreign-owned venture. Alaska and Hawaii are omitted from consideration because foreign firms may locate facilities in these states for a unique set of reasons (i.e., proximity to the Far East and access to mineral resources). Data on planned FDI in new plants were obtained from the U.S. Department of Commerce, International Trade Administration (ITA) (1987-94). The year 1994 was the last year in which the ITA collected these data. ITA also reports data on other types of FDI such as mergers and acquisitions, plant expansions, joint ventures, equity increases, and real property purchases. These data have been used in prior studies of FDI location (Coughlin, Terza, and Arromdee 1991); however, they are less suitable for addressing questions raised in this study because they are more likely to reflect past, rather than current, location decisions. Also, ITA reports values of FDI by manufacturing sector and by state. These data are missing for about 42 percent of new plant investments reported; in consequence, they are not used in the empirical analysis presented below because they are unlikely to be representative of the spatial distribution of the value of FDI that actually occurred. In any case, the FDI data used here are similar to those applied (and described more fully) in related studies by Friedman, Gerlowski, and Silberman (1992); Coughlin and Segev (2000); and List and Co (2000). Smith and Florida (1994) and Head, Ries, and Swenson (1994) have looked more specifically at inward FDI to the U.S. from Japan using related data available 
from the Japan Economic Institute. Guimaraes, Figueiredo, and Woodward (2000) also examine the relationship between agglomeration and the location of FDI using the inward FDI data to Portugal.

Table 1 shows a total of 631 investments in new manufacturing plants over the 1987-1994 period. As discussed more fully by Coughlin and Segev (2000), FDI appears to be both industrially and spatially concentrated. Four two-digit manufacturing sectors (out of 20) received 329 (52 percent) of these investments. Ten states (California, Georgia, Indiana, Kentucky, Michigan, North Carolina, Ohio, Tennessee, Texas, and Virginia) received 25 or more investments, while five states (Idaho, Montana, North Dakota, South Dakota, and Wyoming) received none. Friedman, Gerlowski, and Silberman, who studied the 1977- 1988 time period, found that the U.S. received about 78 FDIs per year. Similarly, during the 1987-1994 time period, about 79 such investments in new plants flowed to the U.S. every year. Thus, the U.S. has attracted foreign new plant investment at a steady rate over the last two decades.

Explanatory variables are similar to those used in previously cited U.S. studies of the location of FDIs. All explanatory variables are measured in 1986, the year prior to the start of the sample period for FDI. This approach may reduce sources of simultaneous equation bias in the resulting estimates; however, it does not eliminate the possibility of this problem. For example, states that had persistently lacked success in FDI attraction before the sample period began may have made comparatively large promotion expenditures in 1986, only to find their efforts unrewarded in later years. This type of reverse causation may have been a problem in other studies (e.g., Lugar and Shetty 1985) that reported a negative relationship between FDI attraction and promotion expenditures and may result in understating the effect of promotion expenditures on FDI attraction when estimating equation (1). In any case, equation (1) is estimated using a relatively full set of explanatory variables measuring agglomeration, tax policy, extent of unionization, and other factors that may also account for a state's historical record in attracting FDI.

Definitions, sample means, and standard deviations of each explanatory variable are presented in Table 2. These variables measure access to markets (gravity weighted state personal income and whether a state has a container port), production costs (average manufacturing production wage, the percentage of manufacturing workers unionized, and manufacturing worker productivity), environmental protection expenditures (pollution abatement operating expenditures per dollar of value added), taxes (a proxy for the state's effective corporate income tax and whether the state used worldwide unitary taxation), agglomeration economies (population density and number of manufacturing plants), the unemployment rate, and state promotional expenditures aimed at attracting FDI. Most of these variables have been used in previously referenced studies of inward FDI to the U.S.

Variables measuring access to markets, agglomeration economies, and state promotion expenditures, however, require further explanation. As indicated above, two variables serve as proxies for access to markets, PORT and MARKET. PORT is a dummy variable indicating whether the state has a major shipping container port. MARKET, a distance-weighted sum of personal income in all other states, has been widely used in the literature. This variable for state $i$ is defined as: 


\section{TABLE 1}

Distribution of FDI by State and Industry: 1987-1994

\begin{tabular}{|c|c|c|c|c|c|c|}
\hline STATE & FDI28 & FDI35 & FDI36 & FDI37 & $\begin{array}{c}\text { Other Manufacturing } \\
\text { FDI } \\
\end{array}$ & $\begin{array}{c}\text { All Manufacturing } \\
\text { FDI }\end{array}$ \\
\hline Alabama & 4 & 3 & 1 & 1 & 4 & 13 \\
\hline Alaska & 0 & 0 & 0 & 0 & 2 & 2 \\
\hline Arkansas & 0 & 1 & 0 & 0 & 2 & 3 \\
\hline Arizona & 0 & 0 & 1 & 0 & 1 & 2 \\
\hline California & 3 & 9 & 13 & 4 & 29 & 58 \\
\hline Colorado & 0 & 0 & 1 & 1 & 5 & 7 \\
\hline Connecticut & 0 & 0 & 0 & 1 & 0 & 1 \\
\hline Delaware & 4 & 0 & 0 & 0 & 1 & 5 \\
\hline Florida & 1 & 1 & 0 & 1 & 5 & 8 \\
\hline Georgia & 4 & 5 & 5 & 3 & 23 & 40 \\
\hline Hawaii & 0 & 0 & 0 & 0 & 1 & 1 \\
\hline Iowa & 1 & 3 & 0 & 0 & 7 & 11 \\
\hline Idaho & 0 & 0 & 0 & 0 & 0 & 0 \\
\hline Illinois & 4 & 7 & 4 & 2 & 7 & 24 \\
\hline Indiana & 0 & 2 & 4 & 15 & 19 & 40 \\
\hline Kansas & 1 & 2 & 0 & 0 & 3 & 6 \\
\hline Kentucky & 2 & 1 & 3 & 9 & 15 & 30 \\
\hline Louisiana & 2 & 0 & 0 & 0 & 2 & 4 \\
\hline Massachusetts & 1 & 1 & 1 & 0 & 2 & 5 \\
\hline Maryland & 0 & 1 & 0 & 0 & 8 & 9 \\
\hline Maine & 0 & 0 & 0 & 1 & 0 & 1 \\
\hline Michigan & 4 & 2 & 6 & 10 & 10 & 32 \\
\hline Minnesota & 0 & 0 & 0 & 0 & 1 & 1 \\
\hline Missouri & 1 & 0 & 1 & 2 & 3 & 7 \\
\hline Mississippi & 0 & 0 & 0 & 0 & 1 & 1 \\
\hline Montana & 0 & 0 & 0 & 0 & 0 & 0 \\
\hline North Carolina & 9 & 8 & 3 & 4 & 30 & 54 \\
\hline North Dakota & 0 & 0 & 0 & 0 & 0 & 0 \\
\hline Nebraska & 0 & 0 & 1 & 0 & 0 & 1 \\
\hline New Hampshire & 0 & 1 & 0 & 0 & 0 & 1 \\
\hline New Jersey & 4 & 3 & 0 & 0 & 7 & 14 \\
\hline New Mexico & 0 & 1 & 2 & 0 & 1 & 4 \\
\hline Nevada & 0 & 1 & 0 & 0 & 4 & 5 \\
\hline New York & 2 & 1 & 1 & 1 & 16 & 21 \\
\hline Ohio & 8 & 2 & 5 & 17 & 15 & 47 \\
\hline Oklahoma & 2 & 0 & 0 & 0 & 1 & 3 \\
\hline Oregon & 1 & 0 & 7 & 1 & 10 & 19 \\
\hline Pennsylvania & 4 & 1 & 0 & 0 & 5 & 10 \\
\hline South Carolina & 1 & 3 & 0 & 5 & 14 & 23 \\
\hline South Dakota & 0 & 0 & 0 & 0 & 0 & 0 \\
\hline Tennessee & 6 & 8 & 2 & 6 & 11 & 33 \\
\hline Texas & 17 & 2 & 5 & 2 & 9 & 35 \\
\hline Utah & 0 & 0 & 1 & 0 & 1 & 2 \\
\hline Vermont & 0 & 0 & 1 & 0 & 0 & 1 \\
\hline Virginia & 3 & 5 & 3 & 1 & 16 & 28 \\
\hline Washington & 0 & 1 & 2 & 0 & 9 & 12 \\
\hline Wisconsin & 3 & 1 & 0 & 0 & 1 & 5 \\
\hline West Virginia & 0 & 0 & 0 & 1 & 1 & 2 \\
\hline Wyoming & 0 & 0 & 0 & 0 & 0 & 0 \\
\hline TOTAL & 92 & 76 & 73 & 88 & 302 & 631 \\
\hline
\end{tabular}




\section{TABLE 2}

Determinants of Foreign Direct Investment in Manufacturing: Conditional Logit Model

\begin{tabular}{|c|c|c|c|}
\hline EXPLANATORY VARIABLE & DEFINITION $^{\mathrm{a}}$ & $\begin{array}{c}\text { MEAN } \\
\text { (Std.Dev.) }\end{array}$ & $\begin{array}{c}\text { EQUATION } \\
\text { (t-statistics) } \\
\end{array}$ \\
\hline \multirow[t]{2}{*}{ MARKET } & Gravity adjusted state personal income & 49.737 & -0.006 \\
\hline & & $(90.015)$ & $(-3.046)$ \\
\hline \multirow[t]{2}{*}{ PORT } & $=1$ if state has a major container port & 0.543 & 0.67 \\
\hline & & $(0.498)$ & (4.997) \\
\hline \multirow[t]{2}{*}{ WAGE } & Average state manufacturing production worker wage & 11.414 & -0.148 \\
\hline & & $(1.358)$ & $(-1.93)$ \\
\hline \multirow[t]{2}{*}{ UNEMP } & Percentage of civilian noninstitutionalized state population unemployed & 6.98 & 0.444 \\
\hline & & $(2.202)$ & $(1.15)$ \\
\hline \multirow[t]{2}{*}{ UNION } & Percentage of manufacturing workforce unionized & 20.442 & 0.016 \\
\hline & & $(12.386)$ & $(1.86)$ \\
\hline \multirow[t]{2}{*}{ VALUADD } & Manufacturing value added per work hour & 51.155 & 0.004 \\
\hline & & $(8.86)$ & $(0.424)$ \\
\hline \multirow[t]{2}{*}{ PAOE } & Pollution abatement operation expenditures per dollar value of added & 0.013 & -13.355 \\
\hline & & $(0.01)$ & $(-1.339)$ \\
\hline \multirow[t]{2}{*}{ TAXRATE } & State corp. tax dollars/fed corp. tax dollars from state & 16.857 & 0.013 \\
\hline & & (9.219) & $(2.54)$ \\
\hline \multirow[t]{2}{*}{ UNITARY } & $=1$ if state has worldwide unitary taxation & 0.087 & -0.996 \\
\hline & & $(0.282)$ & $(-4.339)$ \\
\hline \multirow[t]{2}{*}{ POPDEN } & Population of state per square mile & 170.275 & -0.001 \\
\hline & & $(234.408)$ & $(-2.332)$ \\
\hline \multirow[t]{2}{*}{ MANUFACT } & 1000 's of manufacturing plants in state & 7.936 & 0.0623 \\
\hline & & $(8.865)$ & $(9.428)$ \\
\hline \multirow[t]{2}{*}{ PROMOTE } & Millions of dollars spent to attract FDI & 0.403 & 0.739 \\
\hline & & $(0.511)$ & $(4.045)$ \\
\hline \multirow[t]{2}{*}{ PROPOP } & Interaction variable PROMOTE *POPDEN & 88.15 & 0.005 \\
\hline & & $(171.428)$ & $(3.139)$ \\
\hline \multirow[t]{2}{*}{ PROMANU } & Interaction variable PROMOTE *MANUFACT & 5.179 & -0.083 \\
\hline & & $(10.801)$ & $(-5.335)$ \\
\hline Log likelihood & & & -2212.815 \\
\hline Number of Iterations & & & 7 \\
\hline
\end{tabular}

a. All explanatory variables measured in 1986

(2) $\operatorname{MARKET}_{i}=\Sigma\left(P I_{j} / d^{2}{ }_{i j}\right) \quad i \neq j$

where $P I_{j}$ is personal income in state $j$ and $d_{i j}$ is the distance from the largest city in state $i$ to the largest city in state $j$. Use of this variable has two advantages. First, it offers a control for the proximity to end-users that may be sought by firms manufacturing products with high transport costs. Second, it links FDI attraction by one state to economic conditions in others.

Several variables were considered as possible measures of agglomeration economies. Urbanization economies, arising when firms benefit from the overall scale and diversity of cities, were measured by population density $(P O P D E N)$ per square mile of land. We also considered 
measuring urbanization economies using the level of population and the percentage of a state's population living in cities of more than 100,000 persons. These last two variables were not used in the regression analysis presented below, however, because the level of population unadjusted for land area does not control for the extent to which people are spatially concentrated, and the percentage of population living in cities does not directly control for the level of population. $P O P D E N$, on the other hand, controls for both the size of a state's population as well as its land area and adding either of the other two variables to a regression already containing POPDEN appeared to result in a multicollinearity problem.

Localization economies, which arise when firms benefit from the presence of others in the same industry, are measured by thousands of manufacturing plants in a state (MANUFACT). This measure has the advantage of simplicity; however, localization economies may be better measured at a finer level of geographic and industrial detail. Alternative measures considered but not used in the regression analysis included the density of manufacturing plants (plants per square mile), the level of manufacturing employment, and the density of manufacturing employment (employees per square mile) in a state. Variables measuring statewide density of manufacturing activity may be misleading indicators of localization economies because manufacturing activity tends to be located in cities. Also, the number of manufacturing plants and the level of manufacturing employment to some extent measure the same thing as their Pearson correlation is $r=0.96$.

Using explicit measures of potential external economies as determinants of FDI differs from the approach taken by Friedman, Gerlowski, and Silberman (1992), who tried but in the end did not use two variables thought to measure agglomerative tendencies: manufacturing employment and gross product originating in manufacturing. These variables turned out to have high simple correlations with access to markets, 0.933 and 0.943 , respectively. Use of MANUFACT appears to reduce potential for multicollinearity from this source; the simple correlation between this variable and MARKET is 0.154 . Also, the use of a measure of urban agglomeration economies distinguishes this study from that of Head, Reis, and Swenson (1999) who examined only effects of localization economies.

State expenditures on foreign investment attraction (PROMOTE) were obtained from the National Association of State Development Agencies' (NASDA) State Export Program Database. However, reporting problems and inconsistencies are apparent in these data. For example, some states fail to report specific FDI promotion expenditures, but do report the percentage of total economic development expenditures allocated to attracting foreign direct investment. In this case, we approximated the desired expenditure figure by multiplying a state's total economic development budget by the percentage the agency spent on FDI attraction. When this method could not be applied, promotion expenditures were estimated from the percentage of total budget for foreign offices spent on investment attraction. Also, two states had total budgets for foreign offices listed, but the percentage of that budget used for investment attraction was not provided. Here, percent of staff time used for investment attraction multiplied by foreign office budget was used. Finally, North Dakota and Vermont provided no information on their promotional efforts to attract foreign direct investment. This limited the sample to 46 states (the 48 contiguous states minus North Dakota and Vermont). 
These measurement problems together with other considerations suggest that the promotion variable might usefully be interpreted as a marker for a broader range of economic development efforts aimed at attracting FDI. For example, promotion expenditures by a state agency may be complementary with the off-budget efforts of elected officials. Governors as well as key state legislators are frequently involved in attempting to bring new industry to their jurisdictions. The level of state promotion expenditures may also suggest the extent of local interest and ability to accommodate new industry. In any case, empirical results using the promotion expenditure variable are broadly interpreted in the remainder of the paper to include these types of related economic development efforts.

\section{REGRESSION RESULTS}

Table 2 also presents estimates of effects of explanatory variables on FDI in new plants for all manufacturing. As shown, estimates converged in seven iterations. Coefficients from the conditional logit model are reported along with t-statistics. Marginal effects, which can be computed from these coefficients, are discussed later on. A likelihood-ratio test statistic indicates that the null hypothesis of no relationship between the explanatory variables and FDI would be rejected at conventional levels of significance. The equation shown also was estimated (with similar results) without PROPOP and PROMANU; however, these interaction variables were retained because their coefficients are both significantly different from zero. The discussion below first provides an overview of the results and then considers interrelationships between promotion expenditures and measures of agglomeration economies in greater detail.

\subsection{Overview}

In the estimated equation presented, the coefficient of promotion effort on FDI attraction is positive and significant. This outcome is consistent with findings of several previous studies. Coughlin and Segev (2000), however, measured promotion effort as the number of foreign offices and number of staff persons employed in foreign offices and found insignificant coefficients of both variables. The coefficient of POPDEN, the measure of urbanization economies, is negative and significant at the 1 percent level; and the coefficient of the interaction between PROMOTE and POPDEN (defined as PROPOP) is positive and significant. Also, coefficients of MANUFACT, the measure of localization economies, and the interaction of PROMOTE and MANUFACT (defined as PROMANU) are both statistically significant and have positive and negative signs, respectively. Further calculations, explained more fully below, demonstrate that the marginal effects of POPDEN, MANUFACT, and PROMOTE on numbers of FDI investments attracted are all positive.

These results are consistent with findings in related studies. For example, Woodward (1992), while not controlling for urbanization economies, used the number of manufacturing firms at the county level to control for localization economies and found a positive and significant relationship to FDI. Both Coughlin, Terza, and Arromdee (1991) and Smith and Florida (1994) measure localization economies using state manufacturing employment density and report positive and significant results. The former study does not attempt to measure urbanization effects, while the latter measures urbanization economies using both county population and population density. These two variables had positive and significant and insignificant coefficients, respectively. Head, Reis, and Swenson (1999) measure localization economies as 
the number of manufacturing firms, both in total and of Japanese origin, within a state and in bordering states. They found these variables to be strongly linked to FDI attraction. More recently, List and Co (2001) found a positive and significant relationship between the number of manufacturing plants in a state and FDI attraction in all industries as well as a positive association between population density and FDI attraction in nonpolluting industries. These results are much like our own and are based on measures of agglomeration economies that are similar to those used here.

In regard to other explanatory variables, coefficients of PORT and WAGE are positive and negative, respectively; and both are statistically significant at the 5 percent level. These results would be expected because states with container ports offer a location advantage to foreign investors, whereas relatively high labor costs would represent a location disadvantage. Also as may be expected, results suggest that states that adopted worldwide unitary taxation (UNITARY) received less foreign investment than did other states. The negative and significant coefficient of $M A R K E T$ suggests that proximity to consumers is not the chief location consideration among foreign manufacturing firms.

On the other hand, TAXRATE and UNION both have positive and significant effects on FDI. Previous studies of inward FDI to the U.S. have found mixed results for both variables, and it might be useful to speculate as to possible reasons for this outcome. Regarding UNION, after controlling for the average manufacturing production wage, the percentage of unionized manufacturing workers in a state may serve as a proxy for more profitable locations with better quality workers. Also, regarding the tax variable, firms that are based in Japan and the United Kingdom receive tax credits at home against tax payments made in the U.S., a policy that reduces incentives to avoid comparatively high-tax U.S. states. In this study, firms based in these two countries made 428 of the 630 (68 percent) investments considered. Finally, the Table 2 regression shows that pollution abatement operating expenditures (PAOE), state unemployment rates (UNEMP), and value added per work hour in manufacturing (VALUADD) are unimportant determinants of the number of FDIs.

\subsection{Interactions Between Promotion and Agglomeration}

As indicated in the introduction, the main purpose of this paper is to analyze tradeoffs between promotion expenditures and two types of agglomeration economies. A convenient way to begin to quantify these tradeoffs is to express the estimates reported in Table 2 as marginal effects. In the conditional logit model, marginal effects are calculated using partial derivatives of the estimated equation reported in Table 2 together with information from Table 1 (Greene 2000, p. 863). For example, the marginal effect of a small increase in promotion expenditures on the probability of FDI attraction $\left(M E_{P}\right)$ is

\section{(3) $M E_{P}=(\beta+\gamma * P O P D E N+\alpha * M A N U F A C T) P(1-P)$}

In equation (3), $\beta$ denotes the coefficient of PROMOTE, $\gamma$ denotes the coefficient of PROPOP, $\alpha$ denotes the coefficient of PROMANU, and $P$ denotes the share of foreign direct investment. This equation can be numerically evaluated for either a particular state in the data set or for the "average" state (see below). Before doing so, notice that equation (3) illustrates that in the conditional logit model, the marginal effect of any explanatory variable on the probability of 
receiving FDIs is equal to zero if $P=0$. Thus, an implication of this model is that states historically receiving little or no FDI, perhaps because of location disadvantages, cannot alter this outcome by increasing promotion expenditures or by other means. Of course, it is possible that with a large enough expenditure of promotion dollars, any state could attract FDI investments. Yet, this aspect of the model appears to be consistent with the historical fact that some states have never received many FDIs (see Table 1).

Equation (3) is numerically evaluated using sample information to compute marginal effects of promotion expenditures for states. Results for the "average" state are presented here. Using sample means of POPDEN and PROMANU (see Table 2) and the fraction of FDI attracted by the average state in an average year $(P=0.02)$ results in $M E_{p}=0.01996$. Thus, an increase in promotion expenditures by one standard deviation ( $\$ 0.511$ million) in the average state raises its annual FDI attraction by about 0.8 investments $(0.01996 \times 0.511 \times 631 \div 8)$. Also, effects of increases in population density or in the number of manufacturing firms can be calculated using an analogous approach. In particular, using the mean values of PROMOTE and $P$ together with coefficient estimates reported in Table 2, the marginal effect of POPDEN on the probability of attracting FDI is $M E_{P D}=0.000019$. Thus, an increase in POPDEN by one standard deviation (238 persons per square mile) raises annual FDI attraction by about 0.362 investments. Correspondingly, the marginal effect of MANUFACT on the probability of attracting FDI is $M E_{M}=0.00061$, and a one standard deviation increase in MANUFACT (8,960 manufacturing firms) raises annual FDI attraction in the average state by about 0.431 investments.

Another perspective on these calculations can be obtained by looking at the tradeoff between the two types of agglomeration economies and promotion expenditures, holding each state's FDI share constant. These calculations show the reduction in either urbanization or localization economies that holds the average state's FDI share constant when the promotion budget changes by one unit (in this case, $\$ 1$ million). For example, to examine the tradeoff between promotion expenditures and population density, totally differentiate the estimated equation reported in Table 2 and set the differentials of all variables except PROMOTE, POPDEN, and PROPOP equal to zero. The result, after rearranging terms, is shown in equation (4)

$$
\text { dPOPDEN/APROMOTE }=-M E_{P} / M E_{P D}=-1050.52
$$

where the marginal effects on the right-hand side were discussed above. Thus, for the average state, which spends $\$ 0.403$ million on FDI attraction, an increased budget of $\$ 0.1$ million has the same effect on attracting FDI investments as an increase in population density of about 105 persons per square mile.

The tradeoff between promotion expenditures and the number of manufacturing plants can be calculated in a similar fashion. Again, totally differentiate equation (1), set differentials of all variables equal to zero except for PROMOTE, MANUFACT, and PROMANU and solve for

$$
d M A N U F A C T / d P R O M O T E=-M E_{P} / M E_{M}=-32.7
$$

Thus, an additional $\$ 0.1$ million on promotion by the average state has the same effect on FDI attraction as increasing the number of manufacturing plants by 3,300 . 
Overall, the estimates presented in equation (4) and equation (5) suggest that promotion expenditures can be used as a policy tool to offset the lack of urban population and manufacturing base associated with agglomeration economies. This outcome is important for smaller states because they can control levels of promotion expenditures to overcome location disadvantages that they do not control. However, it should be treated with caution for several reasons. First, as previously discussed, promotion expenditures may be a marker for broader efforts to attract foreign investment. In consequence, marginal effects of promotion expenditures may be overestimated. Second, data on promotion expenditures obtained from the National Association of State Development Agencies are subject to various types of measurement error described previously. Third, the time period used in this analysis, 1987-1994, may not be representative of other time periods, including the current one. Fourth, this study makes no use of data on the value of new plant FDIs. Even though these data are unavailable for over 40 percent the announced investments reported by the U.S. Department of Commerce International Trade Administration, they may be worth analyzing in a later paper. Fifth, the analysis does not address the question of whether additional new plant investment from overseas improves state economic welfare.

\section{CONCLUSIONS}

This paper has applied a conditional logit regression model to estimate determinants of the number of foreign direct investments in new plants in U.S. states. Key results of this analysis show that both promotion expenditures and agglomeration economies are important in attracting foreign plants. Promotion expenditures are interpreted as a marker to include other types of state and local economic development efforts (i.e., off-budget efforts of elected officials) with which they may be complementary. Results show that promotion expenditures can substitute for lack of both urbanization and localization economies and thus appear to be a useful economic development tool as less populous states with comparatively less manufacturing activity compete for investment from overseas.

Also, results presented may prompt additional empirical work to identify state and local characteristics that enhance or inhibit the effectiveness of economic development policies. Further research along these lines might serve as a useful guide to policy in this area. Additionally the results raise some broader issues concerning the role of state and local policy. For example, to what extent do these policy efforts lead away from further spatial concentration of economic activity? How might they have promoted growth of smaller and medium-sized cities at the expense of the largest urban areas? What are the implications for factor movements and the spatial concentration of environmental problems? Do state and local economic development activities lead to improvements in welfare of local residents?

\section{REFERENCES}

Brown, S.P.A., K.J. Hayes, and L.L. Taylor, 2003. "State and Local Policy, Factor Markets and Regional Growth," The Review of Regional Studies 33(1), 40-60.

Coughlin, C.C. and E. Segev, 2000. "Location Determinants of New Foreign-Owned Manufacturing Plants," Journal of Regional Science 40, 323-52. 
Coughlin, C.C., J. Terza, and V. Arromdee, 1991. "State Characteristics and the Location of Foreign Direct Investment in the United States," Review of Economics and Statistics 73, 67583.

Friedman, J., D. Gerlowski, and J. Silberman, 1992. "What Attracts Foreign Multinational Corporations? Evidence from Branch Plant Location in the United States," Journal of Regional Science 32, 403-418.

Graham, E.M. and P.R. Krugman, 1995. Foreign Direct Investment in the United States, Third edition. Institute for International Economics: Washington D.C.

Greene, W.H., 2000. Econometric Analysis, Fourth edition. Prentice Hall: New Jersey.

Guimaraes, P., O. Figueiredo, and D. Woodward, 2000. "Agglomeration and the Location of Foreign Direct Investment in Portugal," Journal of Urban Economics 47, 115-35.

Head, C.K., J.C. Ries, and D.L. Swenson, 1999. "Attracting Foreign Manufacturing: Investment Promotion and Agglomeration," Regional Science and Urban Economics 29, 197-218.

Leichenko, R.M. and R.A. Erickson, 1997. "Foreign Direct Investment and State Export Performance," Journal of Regional Science 37, 307-30.

List, J.A. and C.Y. Co, 2001. "The Effects of Environmental Regulations on Foreign Direct Investment," Journal of Environmental Economics and Management 40, 1-20.

Lugar, M. and S. Shetty, 1985. "Determinants of Foreign Plant Start-Ups in the United States: Lessons for Policymakers in the Southeast," Vanderbilt Journal of Transactional Law 18, 223-45.

McFadden, D., 1974. "Conditional Logit Analysis of Qualitative Choice Behavior," in P. Zarembka (ed.), Frontiers in Econometrics. Academic Press: New York.

Smith, D.F. Jr. and R. Florida, 1994. “Agglomeration and Industrial Location: An Econometric Analysis of Japanese-Affiliated Manufacturing Establishments in Automotive-Related Industries," Journal of Urban Economics 36, 23-41.

Woodward, D.P., 1992. "Locational Determinants of Japanese Manufacturing Start-Ups in the United States," Southern Economic Journal 58, 690-708. 